\title{
Intrarenal Pseudoaneurysm after Percutaneous Nephrolithotomy. Angiotomographic Assessment and Endovascular Management
}

\author{
M. F. Massulo-Aguiar, Christiane M. Campos, N. Rodrigues-Netto Jr \\ Portuguese Beneficent Hospital, Sao Paulo, SP, Brazil
}

\begin{abstract}
We report a case of intrarenal pseudoaneurysm of the right kidney after percutaneous nephrolithotomy (PCNL) in supine position. Diagnosis was established by angiotomography with a 3-D reconstruction. Treatment was successfully achieved by endovascular occlusion using N-butyl-2-cyanoacrylate.
\end{abstract}

Key words: kidney; percutaneous nephrolithotomy; pseudoaneurysm; embolization, therapeutic; angiography; computed tomography

Int Braz J Urol. 2006; 32: 440-4

\section{INTRODUCTION}

Percutaneous renal procedures could lead to several renovascular injuries such as hematomas, arteriovenous fistulas or pseudoaneurysm. The reported incidence of renal pseudoaneurysm following percutaneous nephrolithotomy (PCNL) is 0.6 to $1 \%$ (1) and it is usually assessed by renal angiography. Selective renal embolization is currently considered the most appropriate technique in the treatment for these complications (2). We report a case of pseudoaneurysm following PCNL in supine position assessed by angiotomography with a 3-D reconstruction, managed successfully by endovascular occlusion using N-butyl-2-cyanoacrylate.

\section{CASE REPORT}

A 48-year-old man with a $2 \mathrm{~cm}$ calculus in the lower calyx of the right kidney was submitted to
PCNL in supine position. The procedure was uneventful and no residual stone was observed. Patient was discharged in postoperative day 3 and readmitted with mild hematuria 11 days after the procedure. A persistent 6-day gross hematuria was observed. Ultrasound showed clots in the urinary tract and hemoglobin level decreased to $9 \mathrm{mg} / \mathrm{dL}$; however, homodynamic parameters, such as arterial blood pressure or heartbeats remained normal. Bleeding and coagulation parameters were within normal range preoperatively.

Patient underwent an angiotomography with a 3-D reconstruction (Multidetectors TomographyAquilion 16 channels, Toshiba Corporation, Japan) which diagnosed an inferior pole branch pseudoaneurysm. No other vascular abnormality was seen in the kidney (Figure-1), and the pseudoaneurysm was treated by endovascular embolization with $\mathrm{N}$ butyl-2-cyanoacrylate.

After a right femoral approach under fluoroscopic control (Digital Subtraction 


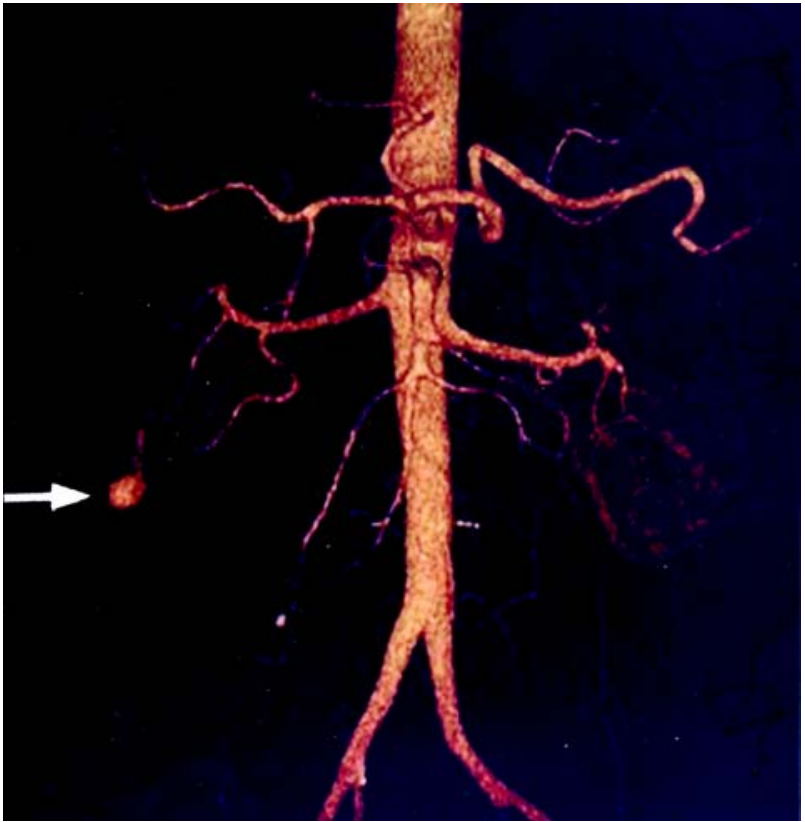

Figure 1 - Inferior pole segmental artery branch with pseudoaneurysm.

Angiography - Biplane Philips - Medical Systems, Best Holland) super selective catheterization into the inferior pole segmental artery was achieved. To delay the polymerization time of N-butyl-2-cyanoacrylate, $0.8 \mathrm{~mL}$ of iodophendylate oil (Lipiodol, Laboratories Guerbet, France) was mixed with N-butyl-2cyanoacrylate. The resulting mixture was injected continuously under fluoroscopic control to prevent reflux into the renal artery. After withdrawal of coaxial catheter, control angiography did not show further opacification of the pseudoaneurysm (Figure-2). The patient was discharged in the second postoperative day.

\section{COMMENTS}

Renovascular injuries may happen following percutaneous renal procedures. A CT examination performed immediately after renal biopsies can reveal up to $90 \%$ hematomas (1). Most lesions presented as hematuria settle completely after few days. However, some of them like pseudoaneurysm could be persistent requiring specific treatment.
Pseudoaneurysm is usually assessed by renal angiography $(1,2)$ leading the possibility of diagnosis and treatment at the same time. In this case, a noninvasive procedure utilizing an angiotomography with a 3-D reconstruction revealed a perfect image allowing a feasible intervention. In fact, clinical diagnosis can be done through invasive (angiography) and non-invasive (angio CT or Doppler ultrasonography) methods. At our institution, angio$\mathrm{CT}$ is available. This kind of management raises the cost but once it is performed, it could not be considered useless because it helps planning endovascular treatment due to the excellent quality of images. It was employed as a non-invasive diagnosis in a patient with persistent hematuria despite overall clinical status improvement.

Selective renal embolization is currently considered as the most appropriate technique in the treatment for renovascular complications with a success rate greater than $80 \%$ and low complication rate (2). Pseudoaneurysms must be occluded with a permanent agent at the fistulous point where the risk of hemorrhage is greater. In contrast to surgery, the

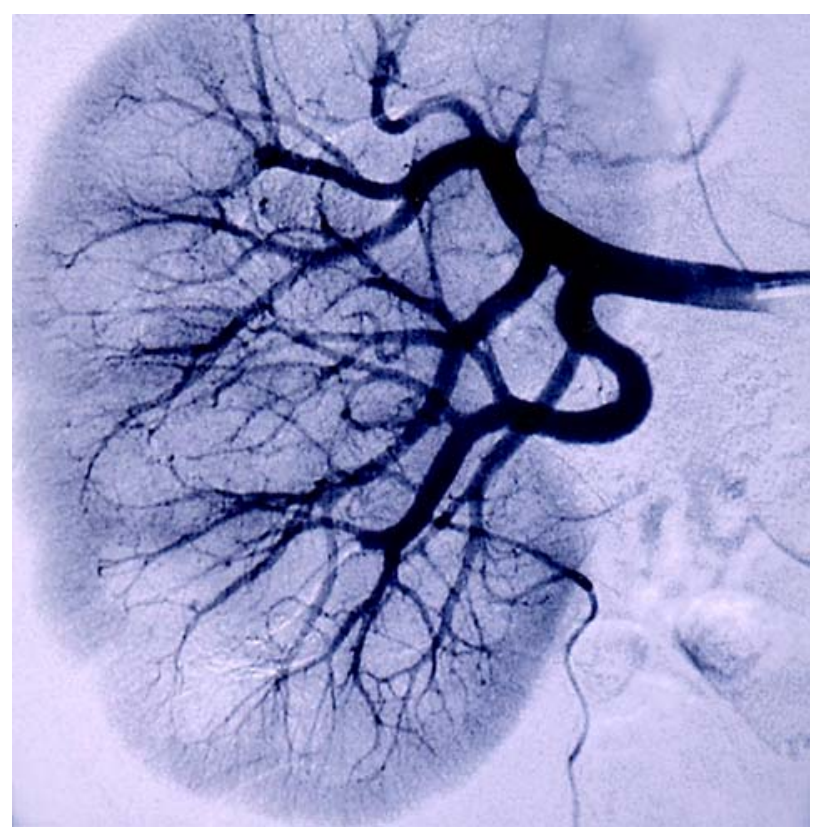

Figure 2 - Control angiography show that there is no opacification of the pseudoaneurysm. 
endovascular management is a minimally invasive procedure that provides the occlusion of the fistula itself as well as the proximal portion of venous drainage and helps salving the kidney in many patients.

Many substances can be employed for embolization like Ethanol (3); gel foam particles (1); microcoil (2); detachable balloons; N-butyl-2cyanoacrylate (2).

Ethanol injected intra-arterially has been used to reduce the vascularity of tumors to facilitate their surgical resection; selective arterial injection exhibit luminal thrombus with endothelial loss and varying degrees of medial necrosis, leading to its occlusion.

Gel-foam embolization has several shortcomings, including: 1) reflux of embolic material into the normal arteries, particularly if a small distal vessel has not been super-selectively cannulated; 2) a larger vessel may be difficult to occlude and it may also in more generalized embolization of the arterial tree; 3) gel foam can undergo resorption and allow recannulation of the vessel.

In moderate-sized vessels, steel coils or detachable balloons may also be used.

Cyanoacrylic glue is a persisting and efficient occluding agent that has been successfully used for more than 20 years in the endoluminal treatment of vascular cerebral malformation (2). In this case, we used N-butyl-2-cyanoacrylate as a permanent embolic agent to avoid the recurrence of the lesion and in the radiology unit of our institution (where the endovascular management was performed), the cyanoacrilate is less expensive than coil.

According to Soyer et al. (2), the use of Nbutyl-2-cyanoacrylate is less expensive than the microcoil cited in the literature. However, in his case, 2 coils were necessary for the complete obliteration of the pseudoaneurysm, thus increasing the cost of the procedure.

\section{CONFLICT OF INTEREST}

None declared.

\section{REFERENCES}

1. Jain R, Kumar S, Phadke RV, Baijal SS, Gujral RB: Intra-arterial embolization of lumbar artery pseudoaneurysm following percutaneous nephrolithotomy. Australas Radiol. 2001; 45: 3836.

2. Soyer P, Desgrippes A, Vallee JN, Rymer R: Intrarenal pseudoaneurysm after percutaneous nephrostolithotomy: endovascular treatment with Nbutyl-2-cyanoacrylate. Eur Radiol. 2000; 10: 1358.

3. Singh B, Sudan D, Singh P, Kaul U: Intraarterial ethanol for the management of iatrogenic renal artery pseudoaneurysm. Cathet Cardiovasc Diagn. 1998; 45: 442-4.
Accepted after revision: November 8, 2005

Correspondence address:

Dr. Maurício F. Massulo Aguiar

Rua Caripunas, 1360 / 801

Belém, PA, 66033-230, Brazil

Fax: + $55913272-9690$

E-mail: mauriciomassulo@hotmail.com 


\section{EDITORIAL COMMENT}

This is a report on the endovascular management of a percutaneous nephrolithotomy (PCNL) complication. This is not a new approach to the management of vascular complications of PCNL, in fact, it is the standard of care. A novel approach to the diagnosis was used with $3-\mathrm{D}$ reconstruction following a CT scan with a 16 channels multidetector

\section{EDITORIAL COMMENT}

The authors present a case report of a patient who had developed an intra-renal pseudoaneurysm following percutaneous stone removal. This finding, in and of itself is not noteworthy, Yet, the interesting finding was that the diagnosis was established using angiotomography with $3-\mathrm{D}$ reconstruction. This is a
CT scan. One could argue that this is an unnecessary expense in a patient with hematuria post PCNL in whom the clinical diagnosis was of a vascular complication and in whom the management needed to be endovascular to begin with. In other words, the clinical diagnosis could have been confirmed at the time of intervention.

\section{Dr. Wilfrido R. Castaneda Professor \& Chair, Department of Radiology Louisiana State Univ Health Sciences Ctr New Orleans, Louisiana, USA E-mail: wcasta@lsuhsc.edu}

non-invasive form of angiographic imaging, which avoids the need for standard, intra-renal angiography. Although the patient did eventually need angiography to perform the endovascular occlusion, the fact that the diagnosis could be made in a non-invasive fashion is worthy of publication.

Dr. Glenn M. Preminger Chief, Comprehensive Kidney Stone Ctr Div of Urology, Duke University Med Ctr Durham, North Carolina, USA E-mail: glenn.preminger@duke.edu

\section{EDITORIAL COMMENT}

Percutaneous procedures are relatively invasive and complications may occur. One of the most significant complications is vascular injury that occurs when the urologist is obtaining intrarenal access. This problem may have several cumbersome consequences, including intraoperative hemorrhage, hypotension, loss of functioning renal parenchyma, arteriovenous fistula, and pseudoaneurysm (1).

The posterior aspect of the lower-pole infundibulum is widely presumed by endourologists 
and interventional radiologists to be free of arteries. It is considered, therefore, to be a safe region through which to gain access to the collecting system and to place a nephrostomy tube. In about $38 \%$ of the kidneys examined, however, an infundibular artery is found in this region (Figure-1). Thus, significant complications may develop as a consequence of a posterior approach through the supposedly vessel-free lower infundibulum (2). In fact, in an experimental study with humans' subjects we found an arterial injury in $13 \%$ of kidneys in which we had made a puncture through the lower pole infundibulum $(3,4)$. That is the case of the present case report.

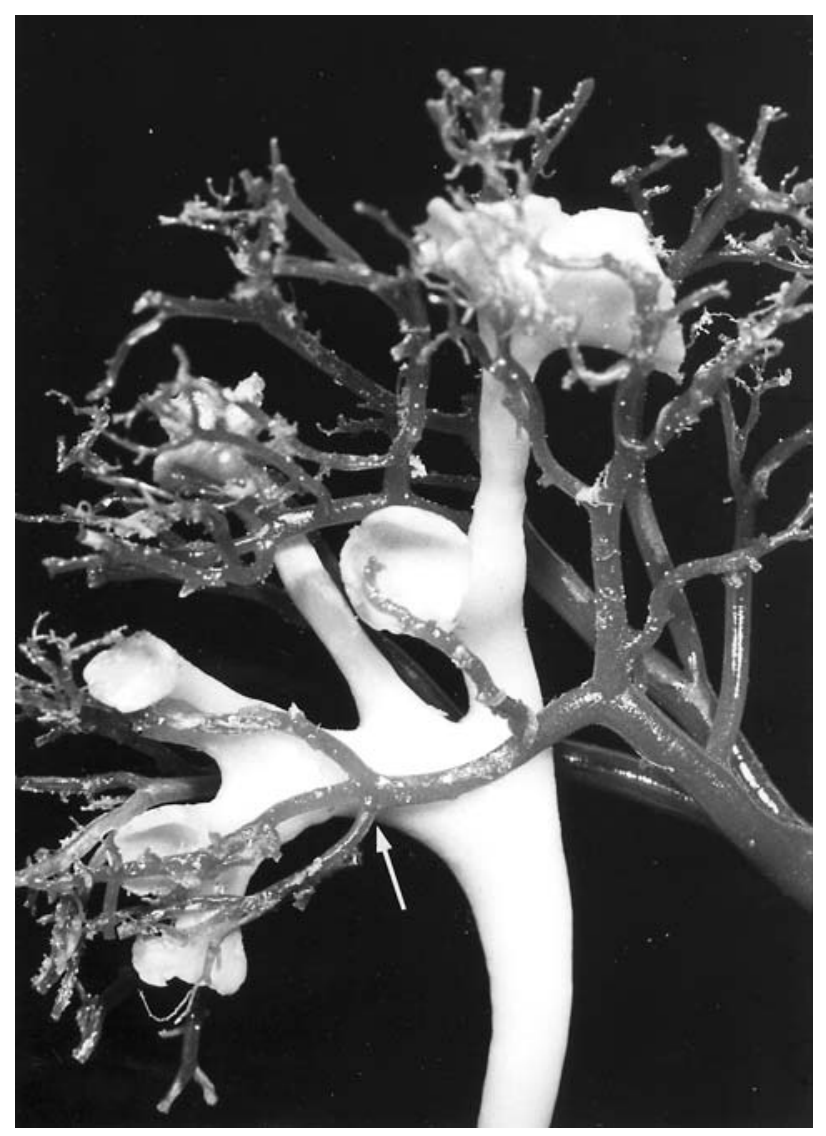

Figure 1 - Posterior view of an endocast (intra-renal arteries and collecting system) demonstrating the posterior branch of the lower pole originating from the posterior division of the renal and coursing in close relationship with the posterior aspect of the lower infundibulum (arrow). From: Sampaio F, Aragão AH: Anatomical relationship between the intrarenal arteries and the kidney collecting system. J Urol. 1990; 143: 679-81.

\section{REFERENCES}

1. Sampaio F: Surgical Anatomy of the Kidney. Part II, Percutaneous Surgery (ed. J.W. Segura). In: Smith's Textbook of Endourology. Edited by Edited by A.D. Smith, G.H. Badlani, D.H. Bagley, R.V. Clayman, G.H. Jordan, L.R. Kavoussi, J.E. Lingman, G.M. Preminger and J.W. Segura. Quality Medical Publishing Inc., St. Louis, USA, 2006 (In Press).

2. Sampaio F, Aragão AH: Anatomical relationship between the intrarenal arteries and the kidney collecting system. J Urol. 1990; 143: 679-81.

3. Sampaio F, Zanier JF, Aragão AH, Favorito LA: Intrarenal access: 3-dimensional anatomical study. J Urol. 1992; 148: 1769-73.

4. Sampaio F: Intrarenal access by puncture. Threedimensional study. In Sampaio F, Uflacker R, eds. Renal Anatomy Applied to Urology, Endourology, and Interventional Radiology. New York: Thieme Medical Publishers, 1993, pp 68-76.

5. Sampaio F: Renal anatomy: Endourologic considerations. Urol Clin North Am. 2000; 27: 585607.

Dr. Francisco Sampaio

Full-Professor \& Chair, Urogenital Research Unit State University of Rio de Janeiro, UERJ Rio de Janeiro, RJ, Brazil E-mail: sampaio@uerj.br 